\title{
Features of simulation of the technical parameters of the packaging line for single food products
}

\section{Anastasiia Derenivska, Liudmyla Kryvoplias-Volodina, Serhii Tokarchuk National University of Food Technologies, Kyiv, Ukraine}

\begin{abstract}
The modern development of scientific and technological process is based on new directions in the creation and design of technical equipment and technical systems. In this article considers research results of packaging line work, as technical system, for single food products which includes different technical equipment. Creating a new product packaging line is involved the need for analysis, systematization of many parameters of constituent mechanisms, devices, modules, packaging equipment, transport systems and choose of optimal ones. The main parameters for the selection of equipment are technological; technical; conditions of compatibility of mechanisms, devices, modules; overall dimensions and weight, electric energy consumption indicators; economic indicators; efficiency of capital costs for its purchase, place and put into operation; payback period of the packaging machine or line. To organize a multi-stage packaging process is necessary to solve the following problems: to distribute the flow of products between the same modules to increase line productivity, to determine the required amount of modules, to determine the operating modes and required productivity of all packing line modules, to create a single orderly lined product stream from many ones in the final stages of packaging, to ensure uniformity of output product based on a uniform calculated clock cycles. Research of the products moving at the stages and levels of packaging, analysis of the intensity of products moving in transport systems and modules give the opportunity to visual observe of the products moving; to find an optimal load and number of the same type of modules; to distribute the products flow between them; to find rational kinematic parameters for work of transport systems and modules; to provide product moving incessant during changing product moving direction and distributing streams during forming a one stream from several; to ensure a uniform release of products based on the same calculated clock cycles of line packaging.
\end{abstract}

Key words: packaging, transporting, food.

Corresponding author: Anastasiia Derenivska

E-mail: anastasya.d@gmail.com

DOI: 10.24263/RES-2019-10

\section{Introduction}

Creating a new packaging line is related to the need for analysis, systematization of many parameters for mechanisms, devices, modules, packaging equipment, 
transport systems and a choice of rational ones [1-5]. The analysis of technical system components which is based on the principle of functional and modular equipment construction was performed with using a multi-stage packaging process and providing a streaming production method. To organize a multi-stage packaging process is necessary to solve the following problems: to distribute the flow of products between the same modules to increase line productivity, to determine the required amount of modules, to determine the operating modes and required productivity of all packing line modules, to create a single orderly lined product stream from many ones in the final stages of packaging, to ensure uniformity of output product based on a uniform calculated clock cycles. A multi-stage packaging process that provides a streamlined production method takes place for packing machines, machine to machine transport systems and handling devices of the packaging line.

The choice and justification of rational parameters in compliance with a type of product, organization of the packaging process, choice of package type, a type of material are ensuring subject to minimal or limited using of production area. The main parameters for the selection of equipment are: technological (productivity, mode of operation, stage of universalization, level of automation, number of performed operations); technical (operating pressure and temperature, frequency of operating entities); conditions of compatibility of mechanisms, devices, modules; overall dimensions and weight, electric energy consumption indicators (in particular consumed electrical power, voltage, etc.); economic indicators (an indicator of the economic viability of using the same equipment in the production process); efficiency of capital costs for its purchase, place and put into operation; payback period of the packaging machine or line.

The purpose of the research is determining the rational parameters of the components of the packaging line by simulating a multi-stage packaging process and providing a streamlined production method.

\section{Result and discussion}

Consider the structure of a flow-technological line with different layout complexity and operating requirements.

The search for functional, parametric and criterion limitations and formulation of a multicriteria structural-parametric method of the packaging machine synthesis was conducted on the basis of functional modules (FM). Mathematically, the input parameters of a future FM modul that is a part of a streamed technological line (STL) are a set of values $x_{1}, x_{2}, \ldots, x_{N}$. These values describe the state of the system at some point in time $t=t_{0}$. Values $x_{i}$ can take on any value, and two different sets of values $x_{1}$ and $x_{2}$ in accordance with two different states. These parameters were denoted as $x_{i}$, $i=1, \ldots n$, given that the number of these parameters $n$ can be large [6-12].

Connection between a design and a technological preparation of production is two-way process, because it is often necessary to modify the product specifications in 
accordance with the existing equipment and vice versa. The correlation between input and output states (process mode $\mathrm{P}$ ) is seen as mathematical transformation of vector $\mathrm{X}$ into vector $\mathrm{Y}$ :

$$
\left\{\begin{array}{l}
Y=F(X) ; \\
\varphi: X \stackrel{F}{\longrightarrow} Y ; \\
P: \text { Res } \rightarrow \text { Prod },
\end{array}\right.
$$

where $\mathrm{X}, \mathrm{Y}$ are in accordance with the set of resources spent and production volume.

An assessment of performance characteristics of the FM in accordance with conditions of operation of FPL is carried out during the modeling process. Information on failures and other defects, changes in operating conditions is used at design and development stage. The relationship between processes enables to measure and analyze of data, use corrective and preventive actions, use loss prevention methods, that will contribute to the continuous improvement of current and future projects and their efficiency. Process control involves control of interactions that helps to eliminate congestion or unnecessary energy costs.

Based on the analysis of the stages of operation of the functional module in the composition of the packaging machine or line, the following product levels were considered: 1- the product as an object that is exploited; 2 - the product as an object of manufacture; 3 - product as an object of improvement. The levels have direct and reverse relationships, that provide a continuous flow of information on the conditions of product using (technological system), and ensuring the product properties at the refinement and manufacture level. This approach makes possible to take into account all the functional features of the product operation in the process of its manufacture and improvement. Usually three heterogeneous components - the technical equipment complex (TEC), the software (S) and the operational staff (OS) can be identified as part of streamed technological system (STS) of the packaging line. These three components have influence on the effectiveness of the system results not in isolation but in close relationship, resulting in it is possible to adjust an efficiency of function performance of a component with help other two components. Such systems are multifunctional and the functions they perform can be significantly different, so the functional approach is used in many issues.

For our research in accordance with some $j$-th function of the technical, software and ergatic (man-operator or group of operators, personnel) groups of components involved in performing this function (Figure 1) are identified among other components. This group of components forms the $j$-th functional subsystem ( $j$-a FSS or FSS $j$ ) in ethe provided system. 


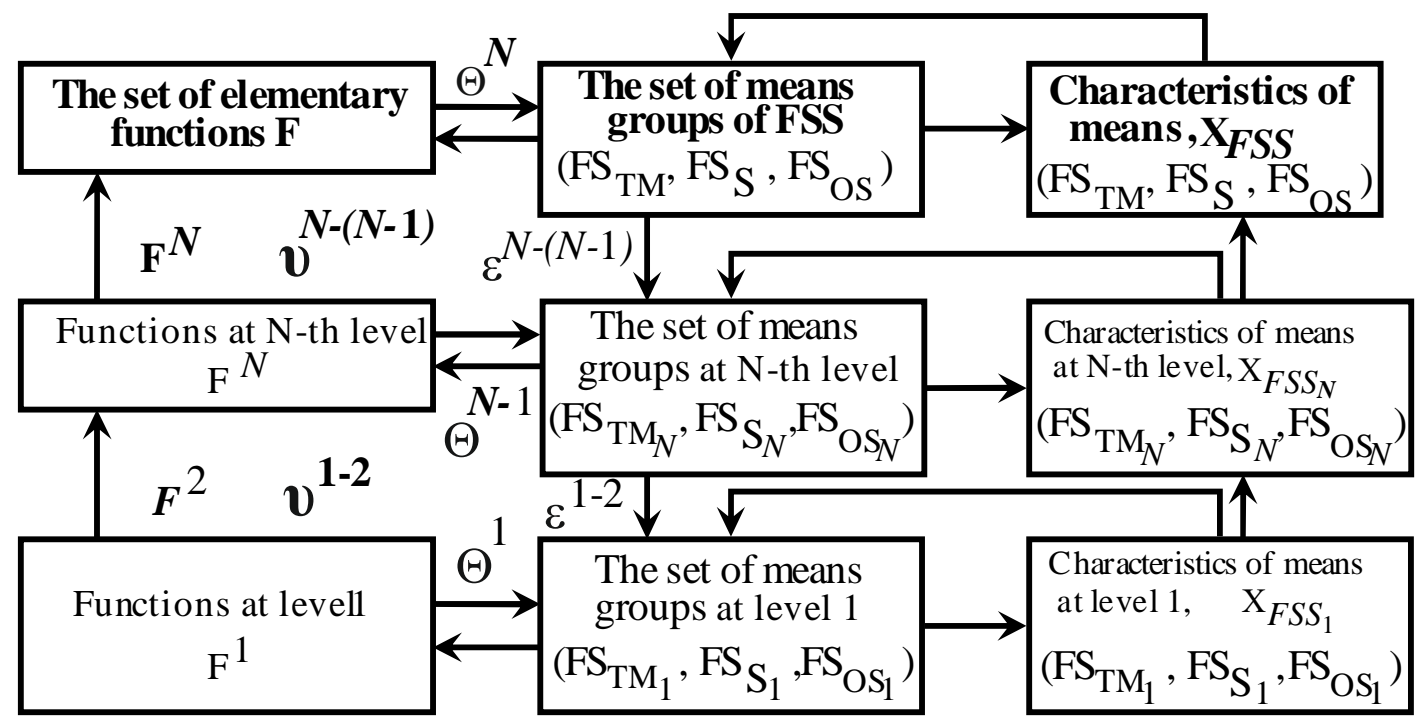

Figure 1. Hierarchical structure of a functional modular subsystem

Usually three components are parts of FSSj . There are a group of technical means that takes part in performance of the $\mathrm{j}$-th function ( $\mathrm{j}$-th functional subsystem TM FSTMj); a group of software that takes part in the performance of the $j$-th function ( $j$ a functional software subsystem $\mathrm{S}-\mathrm{FSSj}$ ); a group of ergatics that takes part in the performance of the $\mathrm{j}$-th function ( $\mathrm{j}$-th functional subsystem $\mathrm{St}-\mathrm{FSOS} \mathrm{j}$ ). One of the most important components of the quality of a modern system, which largely determines the effectiveness of its operation in real operating conditions, is reliability. Trouble-free exploitation and maintenance are the main components of reliability for most systems under consideration.

All groups of means can be divided into two sets of components of the functional subsystem: ready at time $t$ for using and not ready. As a result, set of components of system means can be described as:

$$
F S=F S^{R} \cup F S^{R^{*}} \cup F S^{R^{*}, S},
$$

where $F S^{R}$ - set of component is ready at time $t$ for operating using; $F S^{R^{n}}$ - set of component not ready for operating using (incentive component); $F S^{R^{*}, S}$ - sets of critical components of means system.

Complex indicators of FSS readiness are: the coefficient of readiness $\left(C_{R}\right)$ and the coefficient of operational readiness $\left(\mathrm{C}_{\mathrm{OR}}\right)$. The assessment of the reliability of staff functioning contains the probability of the uptime of the individual performer, taking into account the reliability of the related technical equipment and means of transferring information (software):

$$
P_{F S_{\text {OR }}}=\left(P_{0} P_{1}\left[P_{2}\left(1-P_{0}\right)+P_{0}\right] P_{3}\left(1-P_{4}\right)\right)\left[1-P_{F S_{T M}}\left(1-P_{0}\right)\right]^{2},
$$


where $\mathrm{P}_{i}$ - probability; $\mathrm{P}_{0}$ - probability of perform necessary actions by the staff; $\mathrm{P}_{1}-$ probability of a timely reception and information processing by software; $\mathrm{P}_{2}-$ probability of the right decision made by the staff; $\mathrm{P}_{3}$ - probability of correct a performance operations; $\mathrm{P}_{4}$ - probability of control for performance operations and self-control; $P_{F S_{T M}}-$ probability of technical means failure. A description of the multifunctional reliability system is described for each function (for each FSS) separately. Finding a solution to a design assessment of a reliability system having $N$ functions is to $N$-time repetition of the problem solution for one FSS. Three components (private subsystems - $\mathrm{FS}_{\mathrm{TM}}, \mathrm{FS}_{\mathrm{S}}$ and $\mathrm{FS}_{\mathrm{OS}}$ ), failures (errors) are in FSS. There's a compliance between functions hierarchy and functional subsystem hierarchy. The relationship between the set of elementary functions $(F)$ and the set of means groups $\left(\mathrm{FS}_{\mathrm{TM}}, \mathrm{FS}_{\mathrm{S}}\right.$ and $\left.\mathrm{FS}_{\mathrm{OS}}\right)$ is determined at all levels of the hierarchy. The function $\mathrm{F}_{i j}^{\mu} \in \mathrm{F}^{0}$ complies with a set of means types $\left\{\mathrm{FS}_{l i}^{\mu}\right\}_{Y}(j-$ the hierarchy level function index, 1 - the hierarchy level function number) at each $\mu$ decomposition level. The means type provides a fundamental possibility of function performing. So multiple showing system $\mathrm{F}$ in the FSS subsystem is given.

The system of means is designed on the principle of relationships with levels and formed as a set of elementary means $F S=\left\{F S^{0}, \mathrm{FS}^{1}, \ldots, F S^{\mu-1}\right\}$, each of them ensures the performance of each elementary function of the set $F=\left\{F S^{0}, \mathrm{FS}^{1}, \ldots, F^{\mu-1}\right\}$.

The analysis of functional subsystems shows the multidimensionality of their indicators, so cluster analysis can be used in practical calculations. For proximate classification of functional subsystems It is necessary to carry out rationing of their indicators. One of approaches involves indicators transformation and showing their possible values in the interval $[0 ; 1]$. This is realized through system of the following equations:

$$
\left\{\begin{array}{l}
\mathrm{X}_{F S S_{i j}}^{H}=\frac{\mathrm{X}_{F S S_{i}}-\mathrm{X}_{F S S \min _{j}}}{\mathrm{X}_{F S \max _{j}}-\mathrm{X}_{F S S_{\min }} ;} \\
\mathrm{X}_{F S S \max _{j}}=\max _{i}\left\{\mathrm{X}_{F S S_{j}}\right\}, \\
\mathrm{X}_{F S S \min _{j}}=\min _{i}\left\{\mathrm{X}_{F S S_{i j}}\right\},
\end{array}\right.
$$

where $\mathrm{X}_{F S S_{j}}^{H}$-the rational $i$-th indicator of the $j$-th functional subsystem; $\mathrm{X}_{F S S_{j}}-$ the value of the i-th characteristic of the $j$-th functional subsystem.

The classification of functional subsystems by Shortest-path tree involves the design of the tree and calculating the average distance between $k$ peaks which is taken as a boundary value:

$$
\bar{\rho}=\frac{1}{n-1} \sum_{k-1}^{n} \rho_{k} .
$$


Next, we define the maximum of the distances for which the inequality is true:

$$
\rho_{k^{*-1}}<\rho_{k^{*}}<\rho_{k^{*}+1} .
$$

All found maximum values are compared with the limit value $\bar{\rho}$. Therefore, the functional subsystem can be shown as a set of hierarchically organized set: elementary functions of $\mathrm{F}^{N}$, groups of means $\left(\mathrm{FS}_{\mathrm{TM}}, \mathrm{FS}_{\mathrm{S}}\right.$ and $\left.\mathrm{FS}_{\mathrm{OS}}\right)$ which participate in the implementation of the function at each level and their relevant characteristics $\mathrm{X}_{F S S}$. The set of elementary functions of $\mathrm{F}^{N}$ defines the set of groups FSS $_{i N}^{N}$ and elementary means $\left(\mathrm{FS}_{\mathrm{TM}}, \mathrm{FS}_{\mathrm{S}}\right.$ and $\mathrm{FS}_{\mathrm{OS}}$ ) with a way to use relationships $\Theta^{N}$ between them.

A set of characteristics $\mathrm{X}_{F S S}{ }^{N}\left(\mathrm{X}_{F S S i}{ }^{N} \in \mathrm{X}_{F S S}{ }^{N}\right)$ that ensure the effectiveness of perfomance functions is under limited parameters and formed inside the set $\mathrm{X}_{F S S}^{N}$ by relationships $\Theta^{N}$

Each component of the means system $\mathrm{FS}_{i} \in F S S^{\circ}$ can be described without material $\Theta$ and energy $\varepsilon$ relationships and using readiness R and forced $F$ characteristics:

$$
\mathrm{FS}^{0}=\bigcup_{\mu=1}^{N} \mathrm{FS}^{\mu}\left(\Theta^{\mu}, \varepsilon^{\mu}, R^{\mu}, F^{\mu}\right)
$$

The implementation of this approach shows the controlled formation of the specified STL properties. The process of creating a STL involves a consistent transformation of the needs for the implementation of the purpose into clearly formulated specific requirements.

The characteristics of the quality of products for industrial and technical purposes are determined by the type, composition, and range of parameters of functional subsystems and their components, which perform different functions in the design and manufacturing process.

Beneath is presented an example of a line for packing muffins in Figure 2 as a line for packaging single products with a multi-stage packing process.

The line includes an inlet conveyor belt 1 . The muffins are arranged in a row of 6 pieces and move on this conveyor. Also the line includes handling devices 2 which stops the muffins on conveyor 1 and transports them on conveyor belts 3 , modules 4 for flow pack packaging, modules 5 for packing muffins into a cardboard box, a module 6 for closing a carton box, a module 7 for making a group package, a manipulator 8 , a pallet store dispenser 8 , a module 10 for making a transport package, an outlet roller conveyor 11 . The muffins are arranged in 3 by 3 in a carton box. 


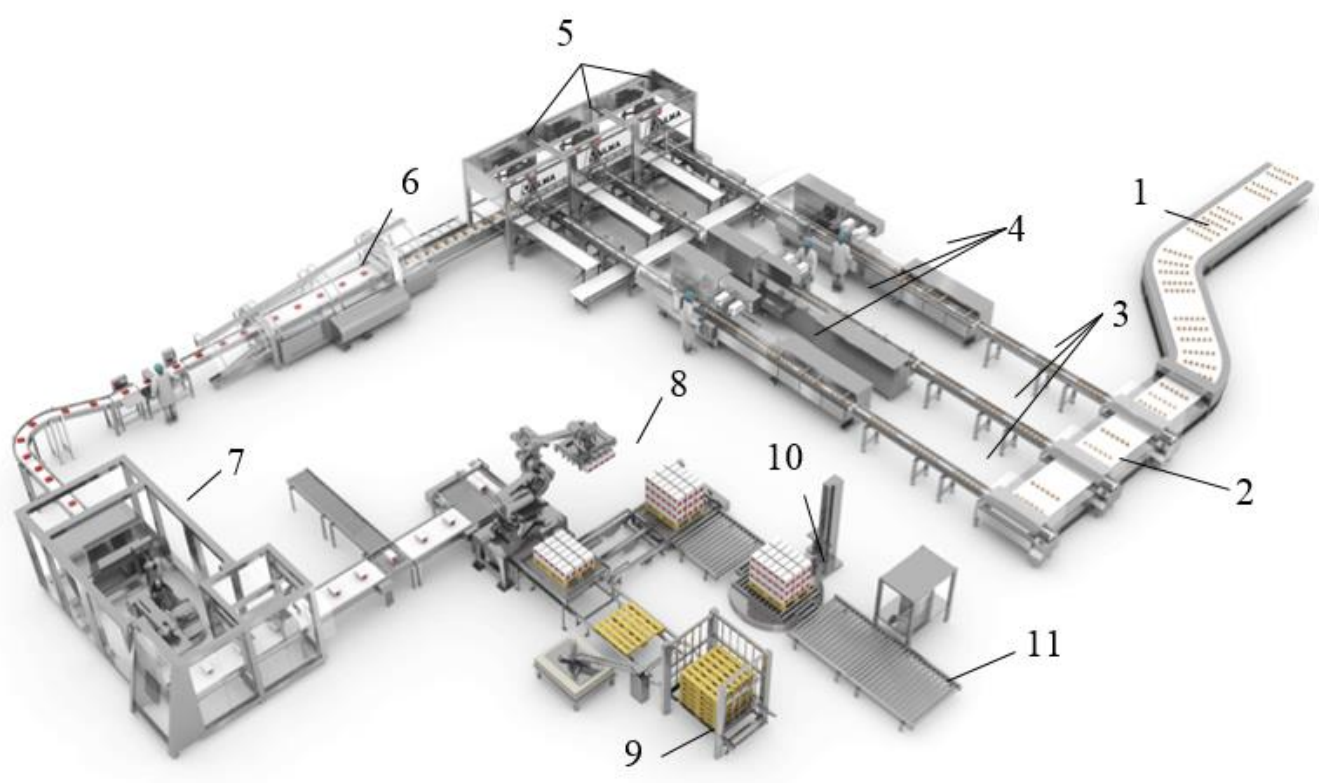

Figure 2. Muffin packaging line layout

The conducted analysis of moving products and packaging materials was allowed to create a layout of material flows moving in the packaging line and to make a conclusion about the need for modeling the areas with the greatest complexity and a lot of technical equipment, specifically at the stage of making consumer cartons.

The layout of muffin packaging line was designed according to the layout of material flow in the AnyLogic program. This layout includes simulation of muffins moving process and packaging muffins into a cardboard box (Figure 3).
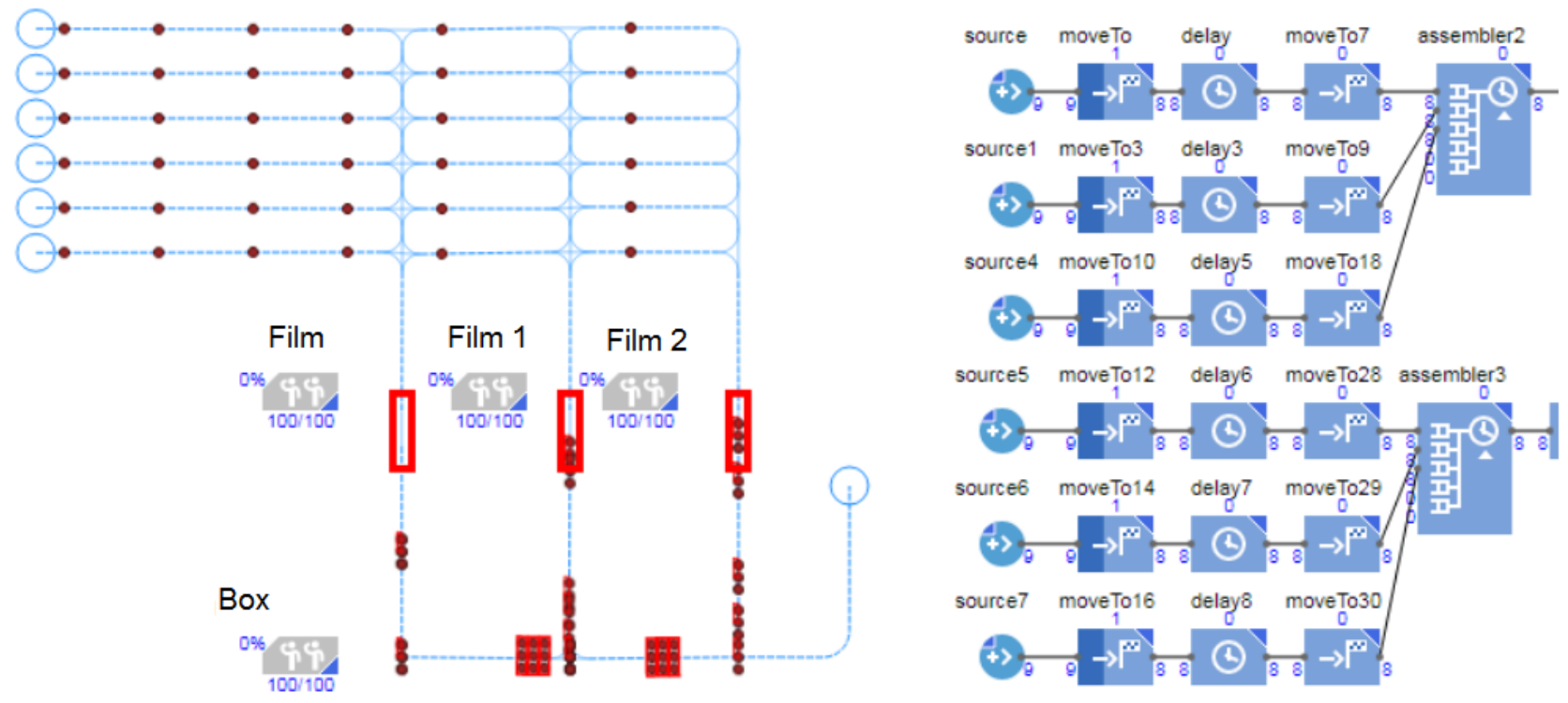

Figure 3. Simulation window for muffins moving which are packed into a cardboard box in the AnyLogic program 


\section{Conclusions}

The result of the simulation is to determine the rational characteristics of work of the functional subsystem for product production. Improvement of existing and development of new methods of multicriteria synthesis for streaming technical system by the set characteristics which are based on systematic approach to the assessment of their quality and competitiveness, is relevant and extremely important task for the domestic engineering . Using the model of effective modes choice for realization of joint interaction of functional modular subsystems made possible to evaluate each machine-building product design in terms of costs for design, production and operation.

Visual observation of the products moving at the stages and levels of packaging, analysis of the intensity of products moving in transport systems and modules give the opportunity: to choose the need load of the same type of modules, to justify its optimal number, to distribute the products flow between them, to find rational kinematic parameters for work of transport systems and modules, to provide product moving incessant during changing product moving direction and distributing streams during forming a one stream from several, to ensure a uniform release of products based on the same calculated clock cycles of line packaging.

\section{References}

1. Burljaj Ju. V., Suhoj L. A. (1975), Oborudovanie dlja ukladki i upakovki shtuchnyh izdelij v taru, Moscow.

2. Palchevskyi B.O., Shapoval O.M., Velykyi O.A. (2013), Optymizatsiinyi syntez funktsionalno-modulnoi struktury pakuvalnoho ustatkuvannia, Lutsk.

3. Derenivska A.V., Kryvoplias-Volodina L.O. (2008), Doslidzhennia protsesiv rozdilennia pidpresovanykh syrnykh blokiv na portsii v perevantazhuvalnykh prystroiakh, Vibratsii v tekhnitsi ta tekhnolohiiakh, 3(52), pp. 84-87.

4. Derenivska A.V. Kryvoplias-Volodina L.O., (2017), Bahatokryterialnyi strukturno-parametrychnyi syntez funktsionalnykh moduliv potokovotekhnolohichnykh pakuvalnykh system, Naukovi pratsi Natsionalnoho universytetu kharchovykh tekhnolohii, 23(5), pp. 98-108.

5. Derenivska A.V., (2014), SADT modeli mashyn dlia pakuvannia produktsii v spozhyvchu taru, Novi idei v kharchovii nautsi - novi produkty kharchovii promyslovosti: mizhnarodna naukova konferentsiia, pp. 357-359.

6. Gavva O.M., Kryvoplias-Volodina L.O., Derenivska A.V. (2016), Syntez prostorovykh potokovotransportnykh system linii pakuvannia kharchovykh produktiv, Scientific Works of ONAFT, 80(1), pp. 131-138.

7. Akesson J., Braun W., Lindholm P., Bachmann B. (2012), Generation of sparse jacobians for the functional mockup interface 2.0., Modelica: Proceedings of 9th International Conference, Munich, pp.185-186. 
8. Benveniste A., Caillaud B., Pouzet M. (2010), The fundamentals of hybrid systems modelers. Decision and Control (CDC), Proceedings of 49th IEEE International Conference: Atlanta, Georgia, USA, pp. 21-26.

9. Blochwitz T., Otter M., Arnold M., Bausch C., Clauß C., Elmqvist H., Junghanns A., Mauss J., Monteiro M., Neidhold T., Neumerkel D., Olsson H., Peetz J.-V., Wolf S. (2011), The functional mockup interface for tool independent exchange of simulation models, Modelica: proceedings of 8 th International Conference: Dresden, pp. 105-114.

10. Blochwitz T., Otter M., Arnold M., Bausch C., Clauß C., Elmqvist H., Junghanns A., Mauss J., Monteiro M., Neidhold T., Neumerkel D., Olsson H., Peetz J.-V., Wolf S. (2012), The functional mockup interface for tool independent exchange of simulation models, Modelica: proceedings of 9th International Conference: Munich, pp. 173-184.

11. Kübler R., Schiehlen W. (2000), Two methods of simulator coupling. Taylor \& Francis Journals: Mathematical and Computer Modeling of Dynamical Systems, 6(2), pp. 93-113.

12. Lee E.A., Zheng H (2007), Leveraging synchronous language principles for heterogeneous modeling and design of embedded systems, Embedded software: proceedings of the 7th ACM \& IEEE international conference: Salzburg, Austria, pp. 114-123. 